\title{
DISTURBANCE OF THE CHORIO-CAPILLARIS AND RETINAL DEHISCENCE*
}

BY

\section{C. MICHAELSON}

Haifa, Israel

ATROPHY of the chorio-capillaris is frequently adduced to explain dehiscence of the periphery of the retina. The evidence may be clinical (based on the choroidal thinning frequently seen in the periphery of the fundus in such cases), and microscopic (based on the disappearance of the chorio-capillaris occasionally seen in the affected region). The clinical evidence has usually consisted of the absence or thinning of chorio-capillaris inferred from the ease with which the larger choroidal vessels can be seen against a white scleral background. In the case to be described it would appear that the actual diseased vessels of the chorio-capillaris could be observed.

\section{Case Report}

A male patient was first examined in September, 1950, when he complained of defective vision. His visual acuity then and since has been as follows:

Right eye, $+1 \mathrm{D}$ sph. $+1 \mathrm{D}$ cyl. $180^{\circ}=5 / 12$

Left eye, $\quad+2 \mathrm{D}$ cyl. $180^{\circ}=5 / 24$

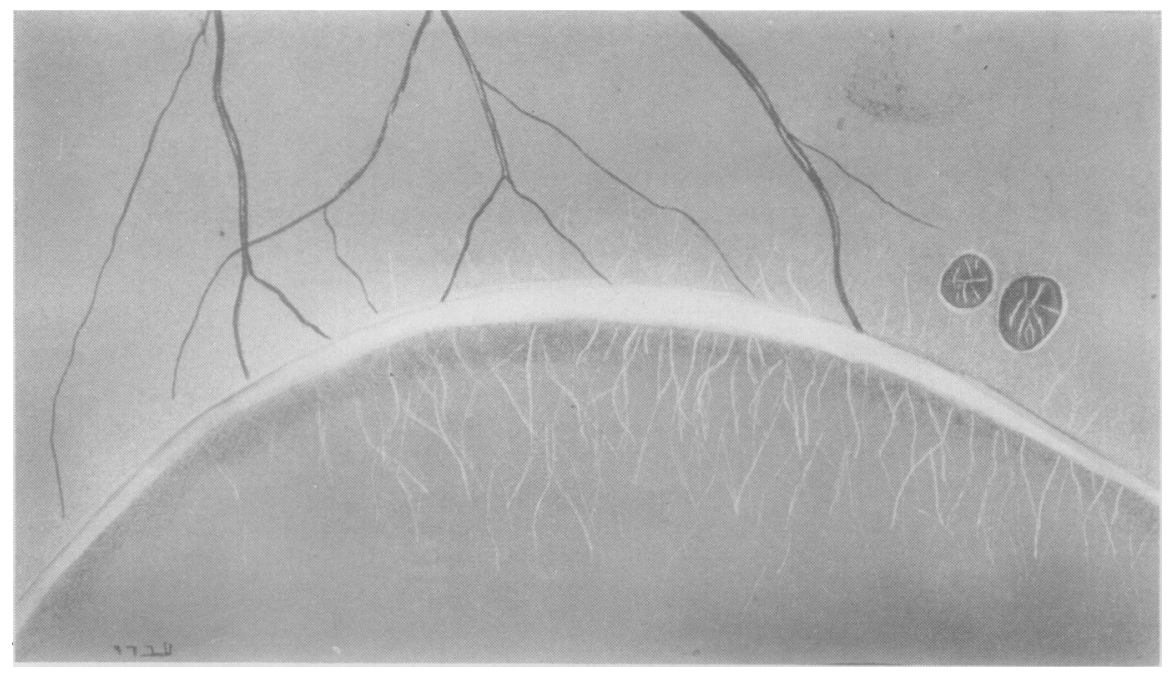

FIG. 1.-Left eye in May, 1951.

*Keceived for publication March 26, 1954. 
No cause for the defective vision was found other than fine changes at both maculae. The visual field showed a central depression for colours but not for white. After several examinations, during which no fundal changes were noted other than the macular ones, the patient failed to attend for 6 montins. On his return in May, 1951, the findings in the left eye showed the appearance seen in Fig. 1. In the neighbourhood of the 5 o'clock meridian there was a dehiscence of the retina and two small retinal holes. Numerous fine interlacing lines could be seen clearly in the dehiscence and hole areas and faintly for a little distance beyond the dehiscence edge. It was considered possible that these white lines represented sclerosed vessels of the chorio-capillaries. One could not, however, regard the possibility of thickened and degenerated Mueller's fibres bordering the spaces of a retinal cystic degeneration and indicating incomplete dissolution of retinal substance. The patient was seen from time to time until May, 1953, when the appearance of the left fundus had somewhat changed. A portion of the dehiscence sketched in May, 1951, was then sketched again at a higher magnification (Fig. 2), to show that many of the white lines now displayed fine red central channels and that small aneurysms could be seen. The patient has been kept under observation since then without any further change being observed. The retinal detachment, the dehiscence and holes, and the sclerosed vessels have remained unchanged. The fundus of the right eye showed no further changes other than an indefinite choroidal disturbance in the periphery of the fundus in the 7 o'clock meridian.

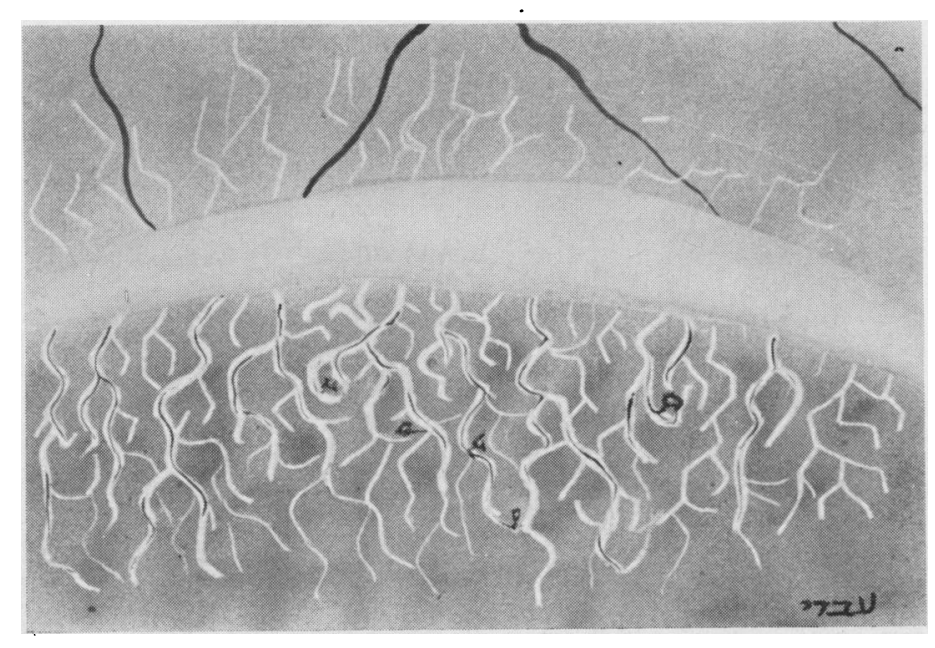

FIG. 2.-Same as Fig. 1, higher magnification.

The sclerosed vessels would appear to be those of the chorio-capillaris as indicated by their general architecture and breadth of mesh. The intensity of the condition in the vicinity of the dehiscence and holes suggests that the vascular sclerosis may have had some part in producing the retinal disturbance.

\section{Summary}

A case is described which shows the association of retinal dehiscence and holes with sclerosis of the chorio-capillaris. 